\title{
The New South Wales Working Party
}

\author{
Beverley Kingston
}

When Frank Crowley sent me to deputise for him at a meeting of the NSW Working Party of the $A D B$ sometime in 1970, I was quite familiar with the project. There was a lot of $A D B$ talk and work in the history department at Monash, where I had been a postgraduate student during the 1960s. From behind his pipe, Geoff Serle oversaw the Victorian entries, and Duncan Waterson was busy with what became his Biographical Register of the Queensland Parliament, 1860-1929 (1972). I happily contributed information to Waterson's database as I worked through the 1860s Queensland newspapers for my PhD thesis on Queensland land legislation and politics. And I had already prepared a couple of entries on obscure Queensland pastoralists for Volume 4 of the $A D B$, published in 1972 .

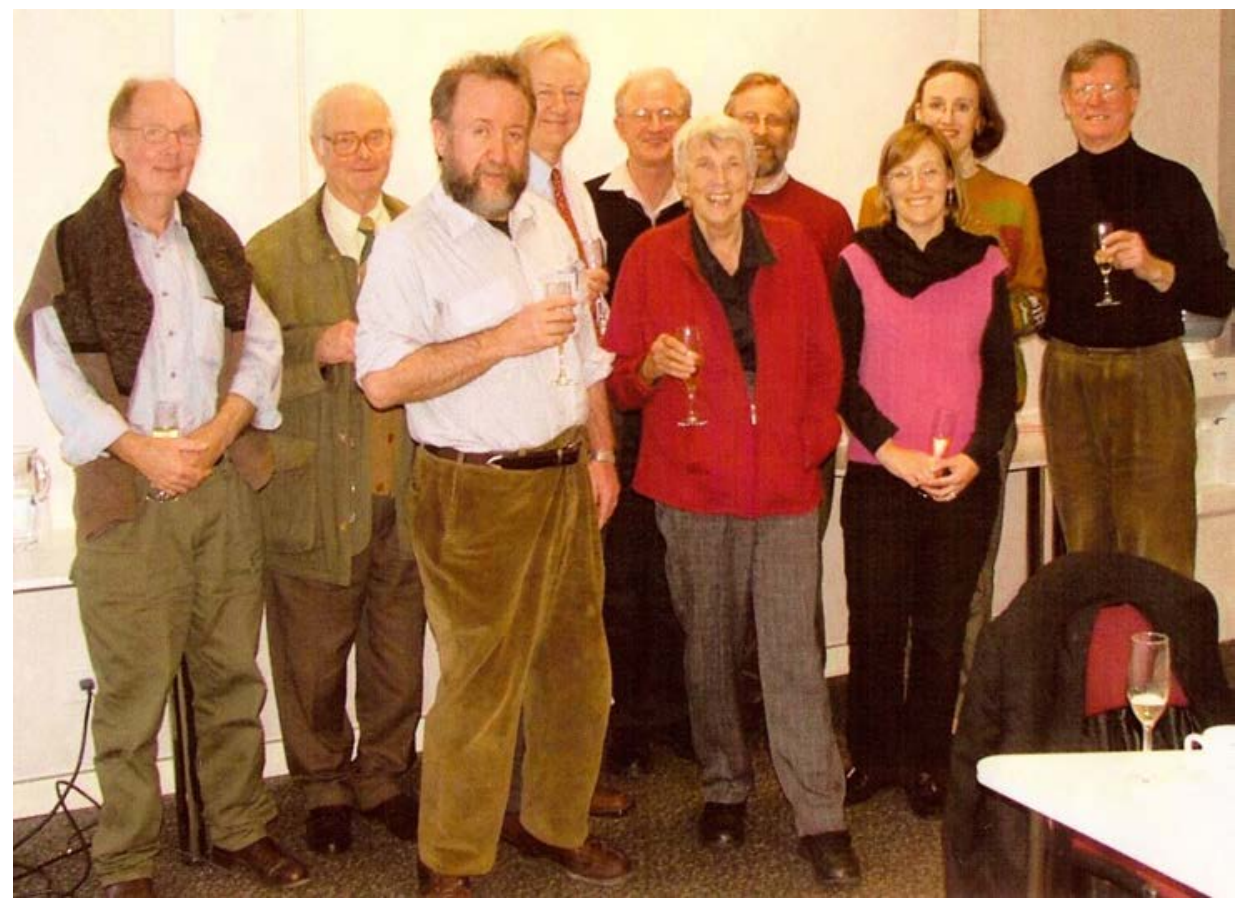

The NSW Working Party, 2009. Left to right: Barrie Dyster, Ross Curnow, Andrew Moore, Stephen Garton, Chris Cunneen, Jill Roe, Murray Goot, Nancy Cushing, Bridget Griffen-Foley, Jack Carmody

By courtesy of Jill Roe 
In 1970 the NSW Working Party met in the office of the state librarian, Gordon Richardson, with its marvellous stained-glass windows and its view across the Botanic Gardens to Sydney Harbour. Over the years we have met in other rooms in the library depending on availability, and until recently were back in that handsome old room, no longer the state librarian's office, but a meeting room named in honour of Jean Garling, a major benefactor of the library. As I recall, there were no formalities at my first meeting. I introduced myself, said I had been sent by Crowley, and spent the next few meetings quietly listening and learning as fast as I could. At the midpoint of the afternoon, tea and coffee and a plate of Arnotts mixed creams were carried in by Richardson's secretary and placed in front of us on the long table. I was greatly in awe of Richardson, a craggy, grizzled Scot, and the group of professors and senior historians like Bede Nairn and Ken Cable who made up the working party. I was probably about half the age of most of them. At first the only other woman was Hazel King, who rarely came because we had moved out of her period. Soon the average age went down somewhat with the arrival of Heather Radi from the University of Sydney, Gerry Walsh from the Australian Defence Force Academy, and the deputy general editor, Chris Cunneen, who began coming with Bede from Canberra to help with the rather complex business of keeping track of the long NSW list.

We were working our way through a thick, stencilled and stapled list of names for possible inclusion in Volumes 3-6 (those who flourished in 1851-90) and were more than halfway through the alphabet. The list, as I recall, was heavy on politicians whose names were mostly unfamiliar to me, though there was a fair selection of writers, artists and other cultural figures about whom I felt more confident. Sportsmen seemed to feature prominently, although this may have been mainly because Nairn and Cable discussed them so enthusiastically. Ken's views on churchmen, of whom there also seemed to be a great many, were rarely questioned.

My arrival was fortuitous, not only because I was a late-nineteenth-century historian, unlike some of the earlier colonial history specialists who no longer had a great deal to contribute, but also because I was, by then, already working seriously on women in Australian history and Volumes 7-12 (those who flourished in 1891-1939), on which we soon began work, covered the early feminist movement.

It was at about this stage that the NSW section of the $A D B$ began to move from the fairly well-known and well-researched colonial period into the relatively under-researched early twentieth century in New South Wales. Nairn, of course, had the 1890s and the early labour movement thoroughly covered-too thoroughly it seemed sometimes. Heather Radi and I took up the challenge of adding more women to the list; we were excited by the possibilities of the new social history for broadening the $A D B$ 's scope. As well, Heather began to remedy 
the lack of systematic biographical material on NSW politicians, especially the non-labour ones, for the period after 1900, and recruited Peter Spearritt and Elizabeth Hinton to help her compile the Biographical Register of the New South Wales Parliament, 1901-1970 (1979). With her help we were able to make better decisions about which of the dozens of minor politicians we could cross out and replace with interesting and significant characters from other walks of life.

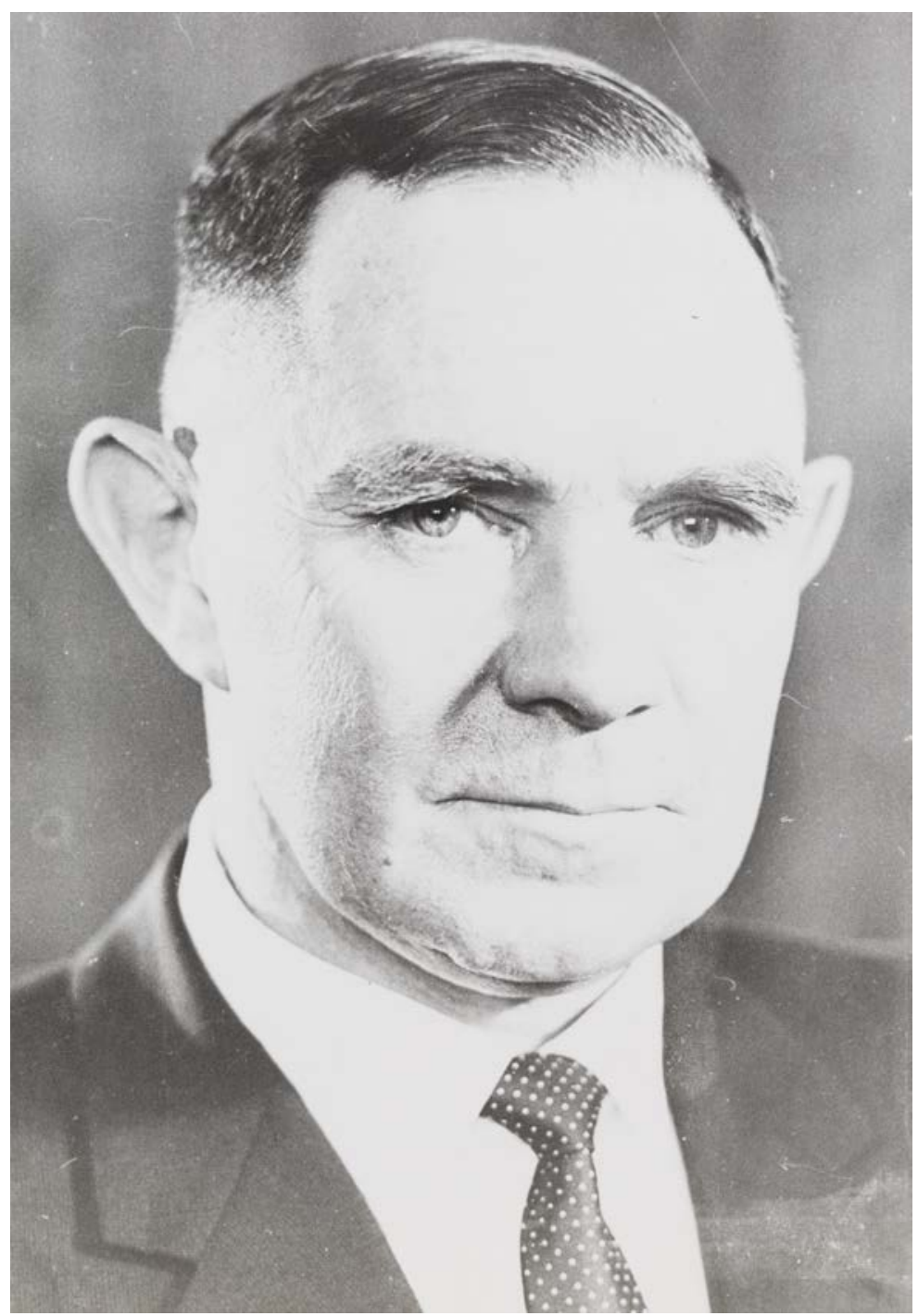

NSW State Librarian, Gordon Richardson, was a founding member of the NSW Working Party and its chair in 1968-73

State Library of New South Wales, n.d. 
Gordon Richardson retired not long after I joined the working party and was succeeded by Russell Doust both as state librarian and as chair of the working party, so the library continued to host our meetings. Russell saw us through Volumes 6-10. By Volume 11 he had retired and was followed by Alison Crook, who assiduously attended meetings though she sometimes left Nairn to chair them. Her successor, Dagmar Schmidmaier, decided she would prefer Alan Ventress, then Mitchell librarian, to deputise for her at meetings, and somehow in 1996 I found myself in the chair. This would not have worked except that Chris Cunneen, who had retired from his position as deputy general editor in Canberra, moved to Sydney and became our record-keeper, chief research organiser and go-between with Canberra. All I had to do was to keep the business moving at a good pace, make sure all issues were canvassed and points of view aired, and sometimes push for a decision.

All these years we have continued to benefit from the hospitality of the State library. This means that we are alerted to the arrival of significant new collections at the library, also to significant research being done by other scholars, many of whom may be potential authors. We hope that the library itself gains something from its links with the research enterprise that the $A D B$ represents. Meetings in the library - long ago seen as neutral ground in the battle between Malcolm Ellis and academe- now mean that working party members can organise precious research time for themselves in the Mitchell Library in conjunction with meetings if they so wish. We have also had substantial and much appreciated assistance from library staff members appointed to deputise for the state librarian, first Margy Burn, who would come to meetings pushing a trolley of reference works when we were drawing up lists for the period 1940-80, then Warwick Hirst, and now Linda West, who books the room, emails the agenda to members and organises the much appreciated afternoon tea.

With the various restructurings of the Editorial Board, there were fewer nominal members of the working party; at its largest in 1988 there were 22 names on the list. For some years now there have been 15 or 16 members, most attending regularly, all hardworking. Meetings have become more frequent in recent years. There used to be months, occasionally a whole year, when nothing needed to be done, but these days more of the work that was once done in the central office in Canberra falls to the working parties. Besides, it seems as if members of the working party appreciate an excuse to escape to the Mitchell Library from time to time. 


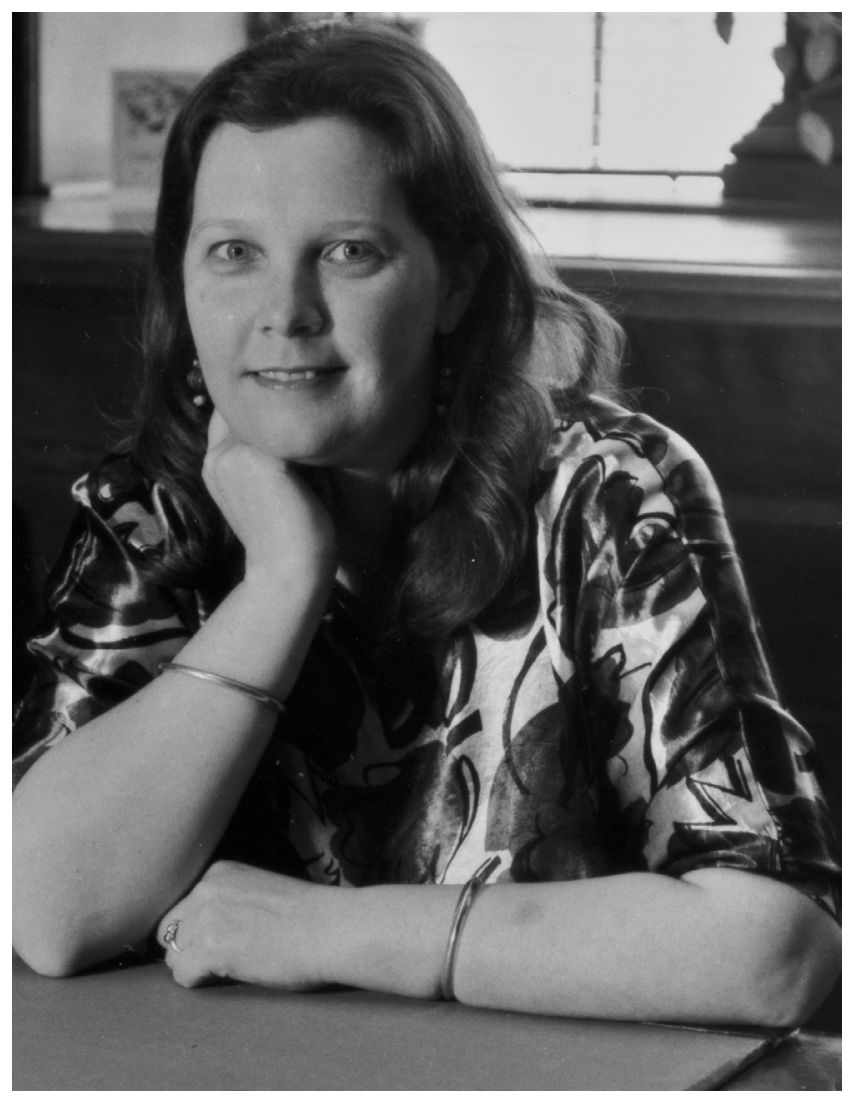

Margy Burn in her office at the State Library of New South Wales, 1993. Margy has continued to promote the $A D B$ in her role as assistant directorgeneral of Australian Collections \& Reader Services at the National Library of Australia

By courtesy of Margy Burn

Our meetings have always been enjoyable, though the reasons for this may have changed over time. For all of us they are a continuing learning experience. A huge amount of information and a great many stories pass over the table. Once almost entirely made up of academic historians and heavily weighted towards the professoriate, the working party has become more diverse in the past decade or so and the informal exchange of gossip between disciplines and institutions can be fascinating. We now have specialists in political science, industrial relations, public administration, law, and Jack Carmody, who covers both medicine and music. Gavin Souter, our expert since the late 1980s on Sydney newspapers and journalists, and memorably, the history of Mosman, retired, and was replaced with media historian Bridget Griffen-Foley, whose internet skills and address book became invaluable. Where once Bruce Mitchell and Greg McMinn came 
from Armidale and Newcastle respectively to broaden our outlook, Nancy Cushing now keeps a close eye on Newcastle and the north and does her best to prevent us from becoming complacent about the kind of women we include, while Glenn Mitchell constantly amazes us with his knowledge of Wollongong people and popular culture. Not everyone enjoys biography, though for those who have stayed with the $A D B$ it has often proved a useful adjunct to their professional research.

Since we completed Volumes 7-12 (1891-1939), something of a pattern has developed for the work on each new period. First it is essential to draw up an initial list of necessary, likely and possible inclusions. This begins with a careful combing of Who's Who in Australia for NSW names, then the $A D B$ 's Biographical Register, other dictionaries, companions, encyclopedias and lists of obituaries. We also ask for advice from professional groups, industry representatives and experts in fields in which we think we need help.

The preliminary list is sometimes twice as long as, or even longer than, the number of names we have been allocated. This list is then sifted, applying an unofficial series of criteria. I think of the sifting as applying a series of different grids, a bit like the coin-sorting machine I knew from my childhood in the bank where my father worked. Other members of the working party have different views of the sifting process. Some are articulated, some instinctive.

We have had substantial discussions from time to time on, for example, the desirability of including famous criminals or celebrities who are household names but significant for no other reason. People who have died young often spark discussion. Is their achievement really significant, how will it compare with their peers who live a longer life, or has it been inflated by the manner or time of their death? The different screening criteria applied by the different members of the working party mean, however, that those who are placed on the list are usually considered from a number of different points of view.

Most members of the working party now have an automatic reaction to an unfamiliar name encountered in their daily lives and these names are raised subsequently. Have we considered this person? Should we be considering this person? So we do. We are no longer worried about finding suitable women for inclusion. They are much more visible these days, though they do tend to live longer and may be forgotten by the time they actually die. But we do keep a close eye on people whose lives have been significant but markedly less flamboyant than the new media celebrities, in business and banking, for example, and have been greatly helped by Barrie Dyster's devotion to entrepreneurs and industrialists. From time to time, we pause to ponder the main developments 
in the demography of the period on which we are working to ask if we are reflecting the patterns of immigration, changing employment, cultural shifts and so on.

As the list is reduced to something like the number allocated, there are further levels of refinement. It has been most interesting to sit down with a list of a dozen or 20 artists, writers, solicitors, politicians, even historians, and try to rank them in order of significance for inclusion. There are often several versions of the same occupational story - the careers of minor politicians or headmistresses, for example, can be fairly repetitive and they cannot all be included. A choice has to be made. Sometimes it is that little extra interesting detail-a noteworthy marriage or a twist in an earlier career. Sometimes it is because better sources exist, or because there is an author known to us who is also willing and able: having a suitable and reliable author to hand can make an immense difference. Occasionally the choice is invidious or seems random or unfair, but there is not enough space to include everyone.

Other State working parties may think New South Wales is being precious about this. Most of them do not have the luxury of this kind of choice. When we were compiling the lists for the supplement volume it became clear that by the time the small States had covered their core list of premiers, chief justices, church leaders and major community figures, they did not have many more spaces to play with. Our core list is not so different in size from Tasmania's or South Australia's, but it constitutes a much smaller proportion of our allocation. New South Wales can afford more variety than other States because we have a larger population and therefore a longer list. Once we have covered the essential and the obvious, we have more space for quirky or unusual people. People who become significant in the arts and cultural life especially have tended to gravitate to Sydney, so there may be a need for some negotiation about whether we include these names or send them back to their State or Territory of origin, and then over the choice of author. All this will undoubtedly change as the online version of the $A D B$ becomes more significant and allocation of space less of a consideration.

One of the most debated questions is the number of words to allocate to any particular person. The assumption is that word length is a measure of worth or significance; however, it is also the case that a person with a complicated story, many changes of occupation or country, a war record, or a complex set of ideas to expound, requires more words than an arguably more significant or influential character who has had an otherwise straightforward life. A morally upright teacher who has never married, or a dedicated scientist who has had an admirable career with a single big discovery, rarely requires more than 500 words. A villain with many aliases, complex personal arrangements and a sticky end needs many more words to set out the facts. 


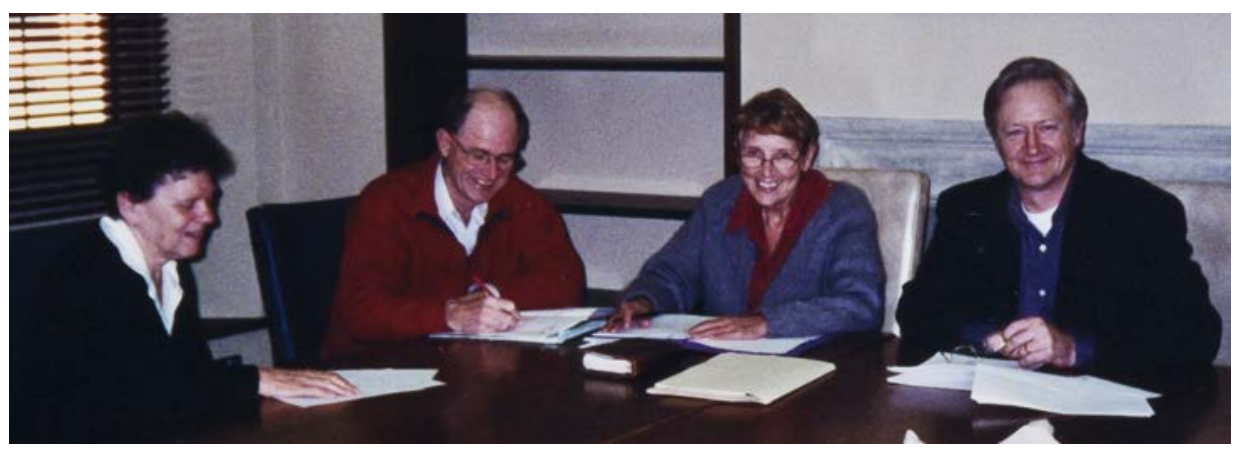

First meeting of $A D B$ Supplement steering committee, 2000. From left: Beverley Kingston, Chris Cunneen (editor), Jill Roe, Stephen Garton

By courtesy of Chris Cunneen

When I first joined the working party in 1970, a majority of the authors were academic historians or postgraduate research students who could be found through the universities. Leonie Kramer, then Professor of Australian Literature at the University of Sydney, was frequently sent a list of literary figures and asked to suggest authors. We still call on the expertise of people who are supervising research to suggest authors. We also have a 'stable' of skilled biographers with expertise in different fields who can be relied on to research and write an entry within their field, but fewer of the authors are now academic historians. The working party has become more sensitive to developments in the research and publishing that now occur outside an academic framework. Sometimes it can be a case of finding a trusted author to counteract what has been judged to be a bad popular biography. Sometimes we find that there is a biography but it is obscure or specialised. Then it seems a good idea to encourage the author to produce a succinct piece that may reach a different or wider readership. Occasionally authors have found themselves with a subject that develops into a larger project. Sometimes the work involved in researching and writing an entry seems a lot to ask of an author, but the level of commitment and professionalism demonstrated by authors is a constant source of admiration and gratitude (and for asking them to undertake yet another entry).

In addition to its official business of drawing up lists of names and suggesting authors, the NSW Working Party takes a keen interest in all matters affecting the $A D B$. Editorial policy, administrative developments in the central office at the ANU, the treatment of the $A D B$ in reviews, and feedback from the public generally are often discussed informally at meetings. There are some vocal advocates of the $A D B$ among the members. Those of us who have closer links with Canberra and the ANU are frequently quizzed and occasionally asked to raise matters at Editorial Board meetings. 
The NSW Working Party enthusiastically urged adoption of the latest technology when it was first proposed to issue the $A D B$ as a CD-ROM. A little later, as has been told elsewhere, Alan Ventress, who, as Mitchell librarian was keenly aware of the way in which information technology was transforming the library, initiated a discussion at a working party meeting that led, eventually, to putting the $A D B$ online. And the supplement volume was driven from within the NSW Working Party. There is a sense in which the (relatively) selfless commitment of the NSW Working Party (though I am sure this is true of all working parties) to the highest values of scholarship and collaborative research has helped to sustain the $A D B$, especially through its more trying times.

Beverley Kingston taught history at the University of New South Wales for 30 years and is currently an honorary research fellow in the School of History at the UNSW. She has been a member of the NSW Working Party since 1974, its chair since July 1994 and has served on the Editorial Board since August 1996. 